Clinical Practice
Nephron Clin Pract 2011;119:c293-c300

DOI: $\underline{10.1159 / 000329671}$
Received: January 6, 2011

Accepted: May 24, 2011

Published online: September 21, 2011

\title{
Immune Profile and Epstein-Barr Virus Infection in Acute Interstitial Nephritis: An Immunohistochemical Study in $\mathbf{7 8}$ Patients
}

\author{
Abdurrezagh Mansur ${ }^{a}$ Mark A. Little ${ }^{c}$ Weng Chin Oh ${ }^{a}$ Steven Jacques ${ }^{a}$ \\ Peter Nightingale $^{\mathrm{b}}$ Alexander J. Howie ${ }^{d}$ Caroline O.S. Savage $^{\mathrm{a}}$

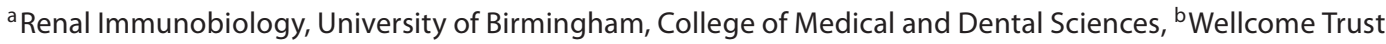 \\ Clinical Research Facility, Birmingham, ' Centre for Nephrology, and d Department of Pathology, University College \\ London, London, UK
}

\section{Key Words}

Allergy · Epstein-Barr virus • Interstitial nephritis •

Immunohistochemistry $\cdot$ T-helper 2

\begin{abstract}
Background: Acute interstitial nephritis (AIN) is a common cause of acute kidney injury and is characterised by a dense interstitial cellular infiltrate, which has not been well defined. Previous studies have demonstrated a correlation between Epstein-Barr virus (EBV) infection and AIN. The purpose of our study was to define the nature of the interstitial immune infiltrate and to investigate the possibility of renal infection with EBV. Methods: Seventy-eight patients with AIN were identified from renal biopsy reports in a single centre over an 18-year period. Immunohistochemical staining was performed to define the cellular infiltrate. In situ hybridization and immunohistology were used to detect EBV. $\boldsymbol{R e}$ sults: A positive correlation between CD68 macrophage infiltration and serum creatinine concentration at presentation was identified. IL-4, eotaxin, CCR3, CCR5 and VCAM-1 were all expressed in biopsies of AIN. Using in situ hybridization and immunohistochemistry, EBV was not detected in any of the AIN sections analysed. Conclusion: This study has
\end{abstract}

assessed the nature of the interstitial infiltrate in AIN. EBV was not detected in the renal biopsies, suggesting that EBV is not a pathogenetic factor in AIN.

Copyright $\odot 2011$ S. Karger AG, Basel

\section{Introduction}

Acute interstitial nephritis (AIN) most commonly presents with sudden onset of renal failure, mid-range proteinuria and pyuria without evidence of bacterial infection of the urinary tract. Renal biopsy demonstrates a dense interstitial cellular infiltrate including $\mathrm{T}$ cells, eosinophils and macrophages [1]. Drug reactions, in particular to non-steroidal anti-inflammatory drugs (NSAIDs) and antibiotics, are the commonest inciting factors of AIN. Less common associations include systemic infections (such as Hantavirus), autoimmune disease and the tubulointerstitial nephritis and uveitis syndrome (TINU).

This paper was presented in part at the Renal Association Annual Meeting, Manchester, 2010.

\section{KARGER \\ Fax +41613061234 \\ E-Mail karger@karger.ch}

www.karger.com
(C) 2011 S. Karger AG, Basel

$1660-2110 / 11 / 1194-0293 \$ 38.00 / 0$

Accessible online at:

www.karger.com/nec
Prof. Caroline Savage

Renal Immunobiology, University of Birmingham

Edgbaston

Birmingham B15 2TT (UK)

E-Mail c.o.s.savage@bham.ac.uk 
CD4+ and CD8+ T cells are common infiltrating cells in this condition [2] and are thought to play a pivotal role in its pathogenesis, with one report of three cases suggesting a T-helper 2 (Th2) skew to the immune response [3]. The lack of a dose-dependent element in drug-induced cases, coupled with the frequent presence of eosinophilia, suggests a hypersensitivity reaction. The current model for the pathogenesis of drug-induced AIN is that drug molecules act as haptens or pro-haptens that undergo a metabolic step converting them into haptens, combining covalently with protein molecules to form novel, non-self antigens [4]. For example, methicillin can bind to tubular basement membrane proteins, thus forming a novel antigen, which is processed and presented on antigen-presenting cells in association with MHC class II molecules, thus stimulating a T-cell-dependent immune response [5].

A number of infectious agents have been associated with AIN, the strongest association with bacterial infection being with Yersinia pseudotuberculosis in Japanese reports [6-10]. Case reports have described associations between infection with various viruses and AIN, with Epstein-Barr virus (EBV) being most commonly implicated [11-12]. The mechanism whereby EBV may cause AIN is unclear, although a contribution by suppressor and cytotoxic $\mathrm{T}$ cells has been described in two case reports [13-14].

We describe here the clinical presentation, outcome, and pathological features of a series of 78 patients with AIN. We investigated the hypotheses that, firstly, the interstitial immune infiltrate in this condition was characterised by markers of Th2 immunity and, secondly, that EBV infection of the kidney was a cause of AIN.

\section{Materials and Methods}

\section{Study Population}

We reviewed reports on renal biopsies carried out on patients with acute renal failure at the Queen Elizabeth Hospital, Birmingham, over an 18-year period, and all patients with AIN not ascribed to infection of the kidney were identified. Acute renal failure was diagnosed by deterioration of renal function over the course of a few days. AIN was diagnosed by acute renal tubular damage associated with an interstitial infiltrate of mixed chronic inflammatory cells, in the absence of pus to suggest ascending infection, and without evidence of leptospirosis or a glomerular disorder such as vasculitic glomerulonephritis, lupus nephritis or acute post-infective glomerulonephritis. We analysed clinical records to establish potential causative factors, degree of renal impairment and treatment received. Frequently, patients were taking more than one drug before admission with AIN, and the most likely drug to have caused AIN was judged on the balance of probabilities. In all cases of TINU, the presence of uveitis was con- firmed by an ophthalmological examination. Each case was followed for at least one year, or until death. Recovery of renal function was defined as creatinine $<120 \mu \mathrm{M}$ at last follow-up.

\section{Immunohistochemistry}

The following mouse monoclonal antibodies, which detected T lymphocytes, macrophages, mast cells, eosinophils and an EBV protein, were titrated on positive control tissues and used for immunostaining on paraffin-embedded sections of renal biopsies: anti-CD3 (1:200), anti-CD4 (1:10), anti-CD8 (1:200), anti-CD68 (1:200), anti-mast cell tryptase (1:200), anti-EBV latent membrane protein-1 (LMP-1, 1:3,200) (all from Dako, Ely, UK) and anti-eosinophil major basic protein (E-MBP, 1:20, Biogenesis, N.H., USA). Appropriate IgG1, IgG2a and IgG2b isotype controls were also included (Dako). In order to retrieve antigen masked by the fixation and embedding process, sections were incubated in boiling $10 \mathrm{~mm}$ citric acid, $\mathrm{pH}$ 6.0, for $30 \mathrm{~min}$. Endogenous peroxidase activity was blocked with $30 \%$ hydrogen peroxide in methanol. Binding was detected using biotinylated goat anti-mouse secondary antibodies. A streptavidin ABC/HRP complex (Dako) was added followed by counterstaining with Mayer's haematoxylin. In some cases, there was not enough tissue to allow immunohistochemical study with each antibody.

Paraffin sections of nasal tissue from a patient with granulomatosis with polyangiitis (Wegener's) was used as a positive control for CD3, CD4, CD8, CD68 and mast cell tryptase. Tissue from allergic nasal polyps was used as a positive control for eosinophil major basic protein, while paraffin sections from a Hodgkin's disease lymph node was the positive control for LMP-1. Control sections of normal kidney were also stained.

Samples of biopsies were snap frozen in OCT-embedding medium (Sakura Finetech, The Netherlands) and stored at $-80^{\circ} \mathrm{C}$ until analysis. Frozen sections were immunostained for various chemokine receptors and other molecules using mouse monoclonal antibodies to CCR3 (1:100, Leukosite, Mass., USA), CCR5 (1:100, R\&D, Abingdon, UK), IL-4 (1:100, Peprotech, London, UK), VCAM-1 (1:50, Dako), eotaxin (1:50, R\&D) and HLA class II (1:50, Dako). Binding was detected with biotinylated goat secondary antibodies and the ABC/HRP complex.

In situ Hybridization for $E B V$

Plasmids pBSJJJ1 and pBSJJJ2 were used, containing EBER-1 and EBER-2 specific fragments respectively (gift from Prof. P.G. Murray, University of Birmingham, UK). Their construction was described previously [15]. In short, EBER-specific fragments derived from plasmids PJJJ1 and PJJJ2 were subcloned into the EcoRI/Hind 3 and BamHI/EcoRI sites of the pBluescript KS vector (GIBCO-BRL, UK), which contained promoters for T7 and T3 RNA polymerases. The recombinant plasmids were purified by standard techniques, linearised with the appropriate restriction enzymes according to the manufacturer's recommendations, extracted with phenol/chloroform/isoamylalcohol and chloroform, precipitated with ethanol and re-dissolved in water. In vitro transcription of the linearised plasmid was carried out in the presence of digoxigenin-11-UTP and either T7 or T3 RNA polymerase.

The appropriate amounts of diluted probe were put onto a dewaxed and rehydrated section, a siliconised coverslip was pressed on to form a sealed chamber, and the slides were left to hybridise at $50^{\circ} \mathrm{C}$ overnight. After washing in standard saline citrate buffer 
Table 1. Demographic characteristics and therapy of three patient groups with acute interstitial nephritis

\begin{tabular}{|c|c|c|c|c|c|c|c|}
\hline \multirow[t]{2}{*}{ Group } & \multirow[t]{2}{*}{ Patients } & \multicolumn{2}{|l|}{ Gender } & \multirow[t]{2}{*}{ Mean age years } & \multicolumn{3}{|l|}{ Therapy } \\
\hline & & $\mathrm{m}$ & $\mathrm{f}$ & & steroid & dialysis & none \\
\hline Drug-induced & 66 & $37(56)$ & $29(44)$ & $61(17-85)$ & $60(91)$ & $22(33)$ & $6(9)$ \\
\hline TINU & 7 & $1(14)$ & $6(86)$ & $42(31-61)$ & $7(100)$ & 0 & 0 \\
\hline No identified cause & 5 & $3(60)$ & $2(40)$ & $44(15-73)$ & $5(100)$ & 0 & 0 \\
\hline Total & 78 & $41(53)$ & $37(47)$ & $55(15-85)$ & $72(92)$ & $22(28)$ & $6(8)$ \\
\hline
\end{tabular}

In the drug-induced group, the types of drug were antibiotics ( $\mathrm{n}=30$; mixed antibiotics, 10; penicillins, 7; amoxicillin, 4; cephalosporins, 3; tetracyclines, 3; ciprofloxacin, 2; trimethoprim, 1); NSAIDs and other analgesics ( $n=20$; diclofenac, 3; ibuprofen, 3; mixed NSAIDs, 3; naproxen, 3; indomethacin, 2; aspirin, 1; mefenamic acid, 1; meloxicam, 1; nabumetone, 1; paracetamol, 1; rofecoxib, 1), and other drugs ( $\mathrm{n}=16$; mixed drugs, 4; co-triamterzide, 2; omeprazole, 2; bendroflumethiazide, 1; chlorambucil, 1; cisplatin, 1; co-amilozide, 1; phenytoin, 1; sulfazalasine, 1; tolbutamide, 1; warfarin, 1). All patients on dialysis received corticosteroids. Figures in parentheses indicate range or percentage.

and blocking in goat serum, hybridization was carried out on deparaffinised sections followed by application of mouse anti-digoxigenin antibody and biotinylated goat anti-mouse secondary antibody. Hodgkin's lymphoma tissue was used as a positive control.

\section{Analysis of Infiltrating Cells}

Aequitas IA image analysis software (Dynamic Data Links, Cambridge, UK) was used to analyse sections. On paraffin sections stained for CD3, CD4, CD8, CD68, mast cell tryptase, and eosinophil major basic protein, the total number of stained cells in each section was counted and expressed as the number of cells/ $\mathrm{mm}^{2}$, the area being defined using the image analysis software after calibration. Frozen sections stained for chemokines, and chemokine receptors could not be examined in the same way because the staining was not sharply localised. On these, the extent of immunostaining was assessed as follows: $1+$, under one third of the tissue stained, $2+$, one third to two thirds of the tissue stained, and $3+$, over two thirds of the tissue stained.

\section{Statistical Analysis}

Kruskal-Wallis testing was used to compare creatinine concentrations and infiltrating cell counts between the AIN subgroups. Spearman correlation was used to assess the association between immunohistochemical findings and clinical phenotype.

\section{Results}

\section{Demographics and Clinical Characteristics}

There were 6,652 renal biopsies, of which 976 were taken for acute renal failure, and AIN was identified in 78 (1\% of the total and $8 \%$ of those where the indication for biopsy was acute renal failure). Their clinical characteristics are summarised in table 1 , divided into three groups, apparently drug-induced, TINU and no identified cause.
TINU syndrome occurred mainly in young women. Drug-induced cases of AIN accounted for most cases in the elderly. Clinical presentation was characterised by a rash in $16 \%$, fever in 35\%, macroscopic haematuria in $28 \%$, and eosinophilia in $15 \%$. The classic triad of fever, arthralgia and rash was present in only 7 (9\%). In 6 of the 7 patients with TINU, the uveitis pre-dated the AIN. Drug-induced AIN was associated with significantly worse renal function at presentation $(600 \pm 46,480 \pm$ 121 and $231 \pm 51$ for drug-induced, TINU and no identifiable cause, respectively, $\mathrm{p}<0.05)$. Nearly all patients were treated with corticosteroids and, if appropriate, with withdrawal of drugs suspected to have caused AIN. Twenty-two patients, all in the drug-induced group, were treated by dialysis. The only variant feature on microscopy was that in 4 cases, all drug-induced, granuloma formation was observed.

\section{Follow-Up}

The differential renal function between the groups was maintained at one year of follow-up $(156 \pm 12,117$ \pm 10 and $126 \pm 12$ in drug-induced, TINU and no identifiable cause, respectively). In 30 of 72 (42\%) and 36 of 70 patients (51\%), serum creatinine concentration fell to $<120 \mu \mathrm{mol} / \mathrm{l}$ by 3 and 12 months, respectively. Druginduced cases of AIN were associated not only with higher serum creatinine concentrations at presentation, but also tended to exhibit poorer renal function at all time points thereafter. Six patients (8\%) died within one year of diagnosis from causes unrelated to their renal disease. 

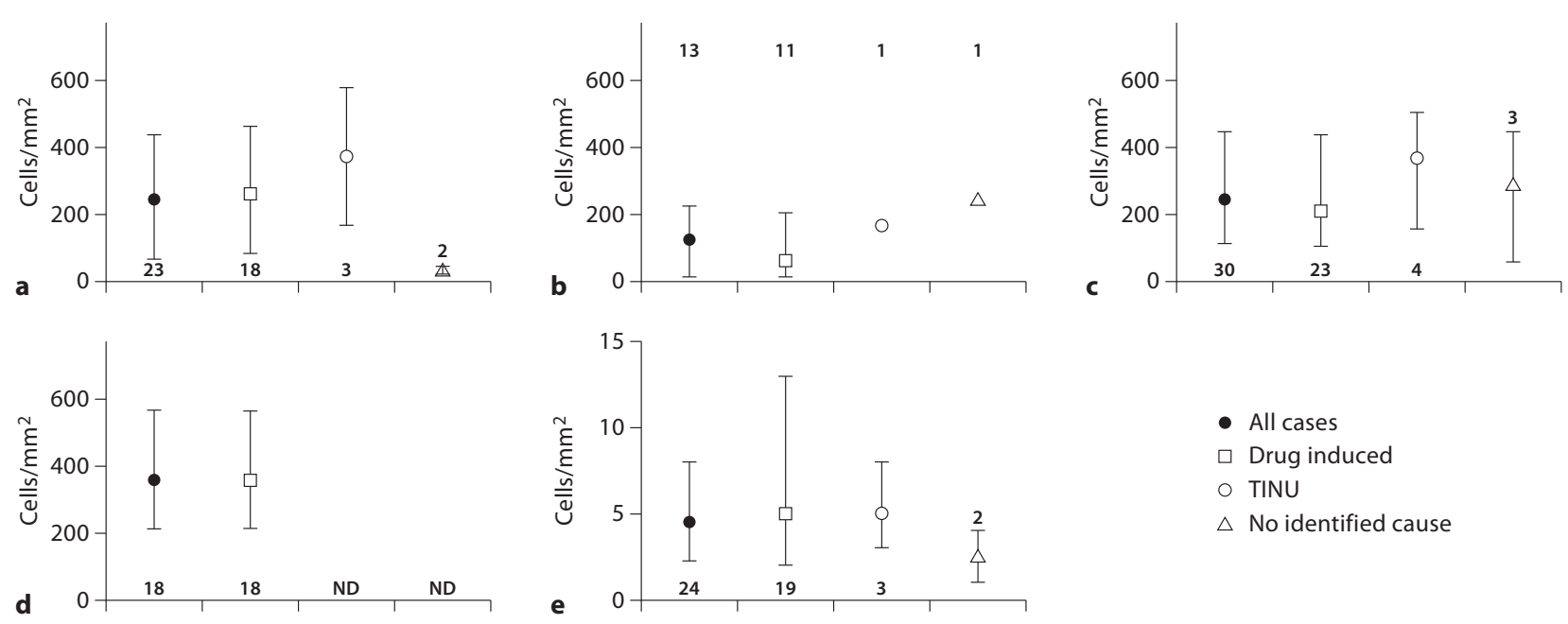

- All cases

$\square$ Drug induced

O TINU

$\triangle$ No identified cause

Fig. 1. Mean numbers of cells per $\mathrm{mm}^{2}$ detected with various antibodies in renal biopsies showing AIN. The numbers adjacent to each column indicate the number of separate cases tested with each antibody. Each data point represents the median \pm interquartile range. a CD3. b CD4. c CD8. d CD68. e EMBP (note the different y-axis).

\section{Immunohistochemistry of Infiltrating Cells}

Figure 1 presents the counts of cells expressing various markers of eosinophils, $\mathrm{T}$ cells and macrophages in a sample of renal biopsies, with representative images in figure $2 \mathrm{a}-\mathrm{e}$. The counts of mast cells in a sample of 23 biopsies, detected by the antibody to mast cell tryptase, were the same as that found in normal renal tissue (data not shown). Although counts of EMBP+ cells were less than for other quantified leukocytes, they were completely absent from normal control kidney. Four frozen sections were available for HLA class II immunohistochemistry, all of which demonstrated $2+$ to $3+$ staining (fig. 2f). There was large inter-biopsy variability in the numbers of infiltrating cells. There were no statistically significant differences in the cell counts between the different subgroups of AIN. The degree of CD68 staining was positively correlated with serum creatinine concentration at presentation ( $r h o=0.65, p<0.005$; fig. $3 b$ ), but not with the likelihood of renal recovery or creatinine level at one year. Conversely, heavy infiltration with eosinophils was associated with a better renal outcome, with prominent eosinophil infiltration restricted to those that recovered renal function (fig. 3a). The ratio of EMBP:CD3 cell count was inversely associated with creatinine level at one year $($ rho $=-0.6, \mathrm{p}<0.005)$.

\section{Chemokine and Adhesion Molecule Expression in AIN}

Frozen sections from 7 cases were examined for the presence of IL-4, eotaxin, CCR3, CCR5 and VCAM-1. Staining of IL-4 was observed in biopsies of AIN compared with normal renal tissue $(2+$ to $3+$ in all sections analysed; fig. $2 \mathrm{~g}, \mathrm{~h}$ ). This was co-localised with eosinophils and CD3+ cells. Eotaxin was detected in the same regions as $\mathrm{CD} 3+$ cells ( $2+$ to $3+$ in all sections analysed; fig. 2i). The receptor for eotaxin, CCR3, was found near infiltrates of eosinophils and $\mathrm{T}$ lymphocytes in the interstitium (2+ in all sections analysed; fig. $2 \mathrm{j})$. CCR5 was found in scattered interstitial and peritubular areas (1+ to $2+$ in all sections analysed; fig. $2 \mathrm{k}$ ). VCAM-1 was found in interstitial infiltrating cells, tubular epithelial cells and endothelial cells ( $2+$ to $3+$ in all sections analysed; fig. 2l).

\section{Findings on $E B V$}

Paraffin sections from all 78 biopsies were stained immunohistochemically for LMP-1, and sections from 34 biopsies were stained for EBER using in situ hybridization. Control sections of Hodgkin's disease demonstrated consistently strong staining using both methods (fig. $2 \mathrm{~m}$, o). There was no detectable evidence of EBV in any of the AIN sections analysed (fig. 2n, p). 
Fig. 2. Immunohistochemical and in situ hybridization findings in renal biopsies in AIN and control tissues. a CD3+ cells in a patient with drug-induced AIN. b CD4+ cells in a patient with drug-induced AIN. c CD8+ cells in a patient with AIN without identified cause. $\mathbf{d}$ Cells expressing eosinophil major basic protein in a patient with drug-induced AIN. e CD68+ macrophages in a patient with AIN without identified cause. $\mathbf{f}$ Cells expressing HLA class II in a patient with AIN without identified cause. g Undetectable IL-4 staining in normal kidney. This is similar to immunostaining for eotaxin, CCR3, CCR5 and VCAM-1 in normal kidney. $\mathbf{h}$ Expression of IL-4 in a patient with AIN without identified cause. i Expression of eotaxin in a patient with drug-induced AIN. j Expression of chemokine receptor CCR3 in a patient with druginduced AIN. k Expression of chemokine receptor CCR5 in a patient with AIN without identified cause. I VCAM-1 expression in a patient with drug-induced AIN. $\mathbf{m}$ Positive in situ hybridization for EBERRNA in a lymph node in Hodgkin's disease. $\mathbf{n}$ Undetectable EBER-RNA in a patient with AIN without identified cause. o Positive immunostaining for the EBV protein, LMP-1, in a lymph node in Hodgkin's disease. p Undetectable LMP-1 expression in a patient with AIN without identified cause.
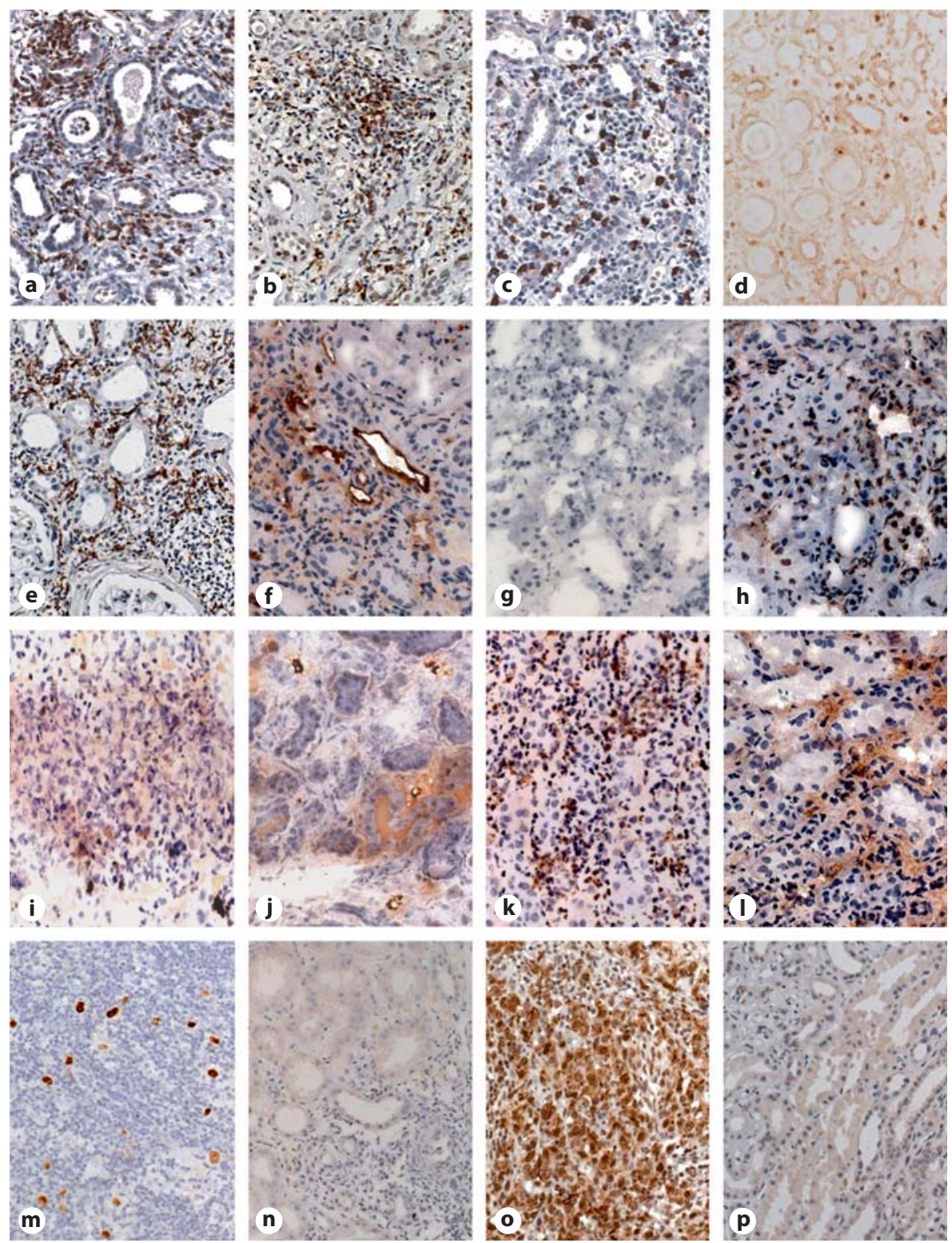

\section{Discussion}

We analysed a series of 78 patients with AIN, to our knowledge the largest series reported. We characterised the infiltrating cells using specific markers for lymphocytes (CD3, CD4 and CD8), macrophages (CD68), eosinophils (eosinophil major basic protein) and mast cells (mast cell tryptase). Our results show a large contribution by $\mathrm{CD} 3+$ and $\mathrm{CD} 4+\mathrm{T}$ cells in AIN. Also, as reported in a number of series, eosinophils were present [16]. In those drug-induced cases assessed with CD68 staining, macrophages were prominent. There was prominent interleu- kin-4, CCR5 and CCR3 staining but no evidence of renal EBV infection.

Previous studies have shown a possible relationship between EBV infection and so-called chronic interstitial nephritis. Becker et al. [17] reported the presence of the EBV genome in proximal tubular epithelial cells of patients with chronic interstitial nephritis. This was detected in the absence of other explanations for the pathological changes. The difference between their important study and ours deserves comment. The main difference is the study population; we included only cases of AIN, whereas Becker et al. [17] primarily included cases of 


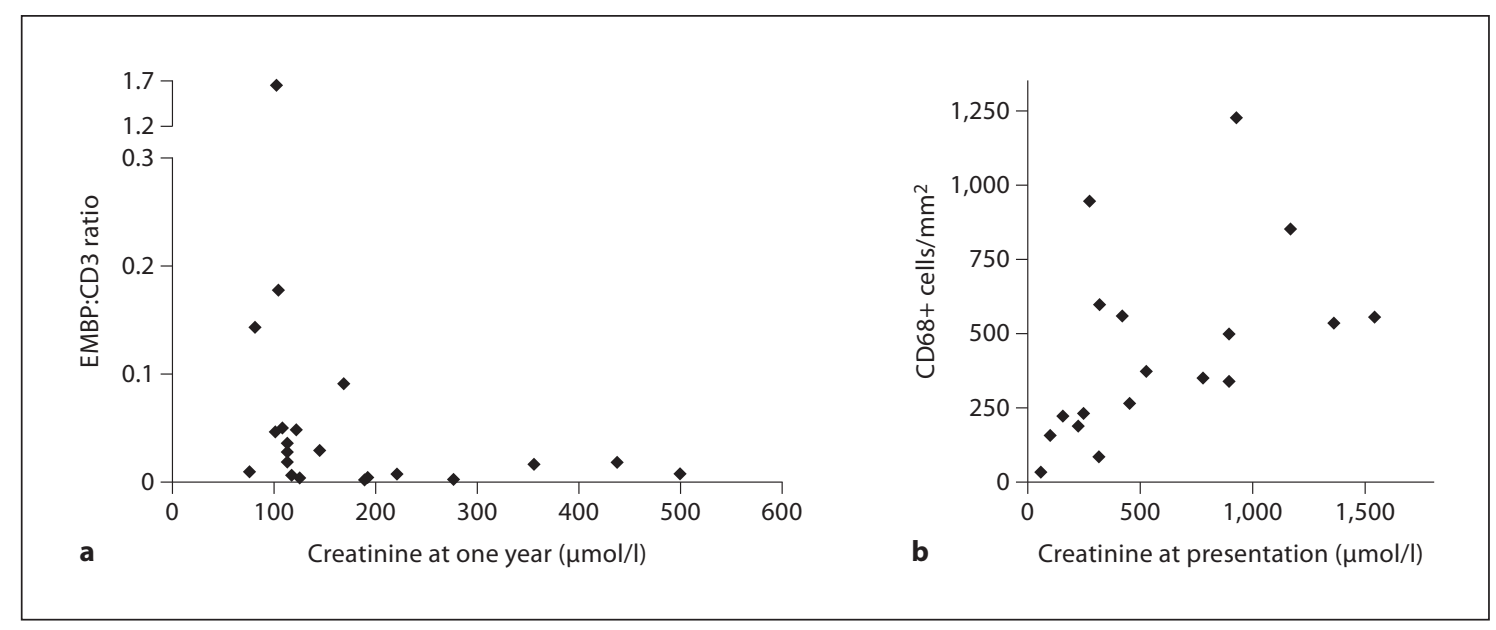

Fig. 3. a Correlation between the ratio of EMBP:CD3 and the creatinine level at one year after follow-up (rho = $-0.6, \mathrm{p}<0.005)$. $\mathbf{b}$ Count of CD68-positive cells in cases of drug-induced AIN related to serum creatinine concentration at biopsy $(\mathrm{rho}=0.65, \mathrm{p}<0.005)$.

chronic interstitial nephritis. Of note, the two cases of AIN they did include were both negative for EBV by both PCR and in situ hybridization. We did not use PCR of renal tissue to look for EBV transcripts, or CD21 immunostaining, so it is conceivable that application of these techniques to our samples could uncover occult EBV. We think this highly unlikely as both of the techniques we applied are highly validated and robust, and demonstrated very clear positive staining in our positive control tissue. It is thus most likely that EBV may be an aetiological factor in chronic unresolving interstitial nephritis but not in AIN.

EBV was also detected in biopsy specimens from patients with IgA nephropathy, membranous nephropathy and focal and/or segmental lesions [18]. This study suggested that EBV directly damaged the glomerular mesangium, and that the damage was mediated by EBV-containing immune complexes in patients with chronic glomerulonephritis. Our study showed that there was no relationship between AIN and EBV, despite extensive testing with two assays in a large cohort. EBER in situ hybridization, in particular, is highly sensitive and is the method of choice for the histological detection of EBV [14]. Our results are consistent with those in a patient described by Mayer et al. [13] who described an individual diagnosed with infectious mononucleosis and who developed acute kidney injury secondary to interstitial nephritis. In situ hybridization of renal biopsy tissue did not reveal evidence of EBER. Another case report by Lei et al. [14] showed EBER in the renal biopsy tissue of a patient with acute kidney injury secondary to EBV-induced infectious mononucleosis, although immunohistochemical stains for EBV latent membrane protein were negative. A retrospective review by Tsai et al. [19] showed that patients who developed acute kidney injury in the setting of an EBV infection also had disseminated multi-organ involvement. Therefore, acute kidney injury may be a useful marker of the severity of the systemic inflammatory response of patients with EBV infection.

Interleukin- 4 is a Th2 cytokine that has several effects on activated $\mathrm{T}$ lymphocytes, including directing the development of Th2 cells and inhibiting the development of Th1 cells. The large amount of staining for IL-4 in AIN suggests a Th2 type response in the kidneys of patients with AIN, although in the absence of staining for specific TH1 markers we are unable to comment definitively on the balance of Th2:Th1 immunity. This is in agreement with the study by Spanou et al. [3] who observed a type IVb hypersensitivity picture in one of their patients, which corresponds with a Th2 profile. An essential role of chemokine receptors is to mediate activation and migration of tissue leukocytes. CCR3 is expressed on human eosinophils, basophils, T helper cells and dendritic cells. We could detect no CCR3-positive cells in normal kidney, whereas in AIN, CCR3 expression was localised to interstitial infiltrating cells. These findings support the presence of a Th2 response in AIN. CCR5 is a receptor for the CC chemokine RANTES, which is expressed in inflammatory kidney diseases. Our study demonstrated the presence of CCR5-positive 
cells in the interstitial infiltrate of patients with AIN, whereas CCR5-positive cells were absent in the normal kidney. This finding suggests that CCR 5 plays an important role in the recruitment of inflammatory cells in AIN. Segerer et al. [20] also demonstrated CCR5-positive cells in areas of interstitial infiltration in biopsies of chronic glomerulonephritis and transplant rejection.

VCAM1 is a tissue-specific leukocyte adhesion molecule expressed at low levels by resting vascular endothelial cells [21]. In addition to its role in recruiting leukocytes to the sites of inflammation, VCAM-1 can produce co-stimulatory signals that are important for the activation of T lymphocytes. Our study showed that in AIN expression of VCAM-1 was detected on interstitial infiltrating cells, tubular epithelium and renal vascular endothelium. Our results were consistent with findings from other studies. The expression of VCAM-1 is upregulated in renal proximal tubular epithelial cells in a variety of inflammatory renal diseases. These include systemic lupus erythematosus, NSAID-induced interstitial nephritis and IgA nephropathy [22]. Seron et al. [23] also showed a marked increase in VCAM-1 expression in AIN due to NSAIDs and in crescentic glomerulonephritis.

Macrophage infiltration is a major feature of glomerular and tubulointerstitial disease. Large numbers of infil- trating macrophages can be found in a variety of renal diseases, such as antineutrophil cytoplasmic antibodypositive glomerulonephritis, lupus nephritis and IgA nephropathy. In this study, a variable number of infiltrating macrophages were found in the biopsies of patients with AIN. There was a positive correlation between the number of CD68+ macrophages and the degree of renal impairment at presentation. This is in agreement with findings in other renal diseases, such as chronic kidney disease [24, 25], IgA nephropathy [26] and crescentic glomerulonephritis [27]. This supports the concept that classically activated macrophages are important protagonists of tubular damage in AIN.

In summary, this study has shown that markers of Th2 immunity are present in the kidneys of patients with AIN, along with findings to suggest that EBV is not a major pathogenic factor in AIN. The severity of the initial injury was associated with the degree of macrophage infiltration, and prominent eosinophil infiltration was associated with improved renal function at one year. These results are important for improving our understanding of the aetiopathogenesis of AIN. The study also confirms that renal dysfunction is reversible in AIN, although the extent that this reflected treatment with corticosteroids cannot be inferred from this observational study.

\section{References}

1 Toto RD: Acute tubulointerstitial nephritis. Am J Med Sci 1990;299:392-410.

-2 Kobayashi Y, Honda M, Yoshikawa N, Ito H: Immunohistological study in sixteen children with acute tubulointerstitial nephritis. Clin Nephrol 1998;50:14-20.

-3 Spanou Z, Keller M, Britschgi M, Yawalkar N, Fehr T, Neuweiler J, et al: Involvement of drug-specific $\mathrm{T}$ cells in acute drug-induced interstitial nephritis. J Am Soc Nephrol 2006;17:2919-2927.

-4 McGurk KA, Remmel RP, Hosagrahara VP, Tosh D, Burchell B: Reactivity of mefenamic acid 1-o-acyl glucuronide with proteins in vitro and ex vivo. Drug Metab Dispos 1996; 24:842-849.

5 Border WA, Lehman DH, Egan JD, Sass HJ, Glode JE, Wilson CB: Antitubular basementmembrane antibodies in methicillin-associated interstitial nephritis. N Engl J Med 1974; 291:381-384.

-6 Runowski D, Szymoniak N, Zaniew M, Piatkowska-Kopczyk M, Wozniak A, Kroll P, et al: Yersiniosis as a cause of acute tubulointerstitial nephritis and acute renal failure case report (in Polish). Wiad Lek 2005; 58(suppl 1):77-80.
Okada K, Yano I, Kagami S, Funai M, Kawahito S, Okamoto T, et al: Acute tubulointerstitial nephritis associated with Yersinia pseudotuberculosis infection. Clin Nephrol 1991;35:105-109.

8 Kobayashi Y, Honda M, Yoshikawa N, Ito H Acute tubulointerstitial nephritis in 21 Japanese children. Clin Nephrol 2000;54:191197.

-9 Fukumoto Y, Hiraoka M, Takano T, Hori C Tsuchida S, Kikawa Y, et al: Acute tubulointerstitial nephritis in association with Yersinia pseudotuberculosis infection. Pediatr Nephrol 1995;9:78-80.

10 Cheong HI, Choi EH, Ha IS, Lee HJ, Choi Y: Acute renal failure associated with Yersinia pseudotuberculosis infection. Nephron 1995; 70:319-323.

11 Helin K, Ekroos H: A case of mononucleosis complicated by acute nephritis. Scand J Urol Nephrol 2002;36:152-153.

12 Norwood VF, Sturgill BC: Unexplained acute renal failure in a toddler: a rare complication of Epstein-Barr virus. Pediatr Nephrol 2002;17:628-632.
13 Mayer HB, Wanke CA, Williams M, Crosson AW, Federman M, Hammer SM: Epstein-Barr virus-induced infectious mononucleosis complicated by acute renal failure: case report and review. Clin Infect Dis 1996;22:1009-1018.

14 Lei PS, Lowichik A, Allen W, Mauch TJ: Acute renal failure: unusual complication of Epstein-Barr virus-induced infectious mononucleosis. Clin Infect Dis. 2000;31:1519-1524.

15 Niedobitek G, Herbst H: Applications of in situ hybridization. Int Rev Exp Pathol 1991; 32:1-56.

16 Hawkins EP, Berry PL, Silva FG: Acute tubulointerstitial nephritis in children: clinical, morphologic, and lectin studies. A report of the Southwest Pediatric Nephrology Study Group. Am J Kidney Dis 1989;14:466-471.

-17 Becker JL, Miller F, Nuovo GJ, Josepovitz C, Schubach WH, Nord EP: Epstein-Barr virus infection of renal proximal tubule cells: possible role in chronic interstitial nephritis. J Clin Invest 1999;104:1673-1681.

18 Iwama H, Horikoshi S, Shirato I, Tomino Y: Epstein-Barr virus detection in kidney biopsy specimens correlates with glomerular mesangial injury. Am J Kidney Dis 1998;32: 785-793. 
-19 Tsai J-D, Lee H-C, Lin C-C, Liang D-C, Chen S-H, Huang F-Y: Epstein-Barr virus-associated acute renal failure: diagnosis, treatment, and follow-up. Pediatr Nephrol 2003; 18:667-674.

-20 Segerer S, Mac KM, Regele H, Kerjaschki D, Schlondorff D: Expression of the C-C chemokine receptor 5 in human kidney diseases. Kidney Int 1999;56:52-64.

-21 Brady HR: Leukocyte adhesion molecules and kidney diseases. Kidney Int 1994;45: 1285-1300.

-22 Tu Z, Kelley VR, Collins T, Lee FS: I kappa B kinase is critical for TNF-alpha-induced VCAM1 gene expression in renal tubular epithelial cells. J Immunol 2001;166:68396846.
23 Seron D, Cameron JS, Haskard DO: Expression of VCAM-1 in the normal and diseased kidney. Nephrol Dial Transplant 1991;6:917922.

-24 Eardley KS, Kubal C, Zehnder D, Quinkler M, Lepenies J, Savage CO, et al: The role of capillary density, macrophage infiltration and interstitial scarring in the pathogenesis of human chronic kidney disease. Kidney Int 2008;74:495-504.
25 Eardley KS, Zehnder D, Quinkler M, Lepenies J, Bates RL, Savage CO, et al: The relationship between albuminuria, MCP-1/ CCL2, and interstitial macrophages in chronic kidney disease. Kidney Int 2006;69: 1189-1197.

26 Myllymaki JM, Honkanen TT, Syrjanen JT, Helin HJ, Rantala IS, Pasternack AI, et al: Severity of tubulointerstitial inflammation and prognosis in immunoglobulin A nephropathy. Kidney Int 2007;71:343-348.

-27 Yang N, Isbel NM, Nikolic-Paterson DJ, Li Y, Ye R, Atkins RC, et al: Local macrophage proliferation in human glomerulonephritis. Kidney Int 1998;54:143-151. 